\title{
The Influence of Atrazine on the Growth, Development and Oxygen Consumption of Pelophylax nigromaculatus Tadpoles
}

\author{
Minyi Huang*†, Qiang Zhao*, Yaqi Zhang*, Yuxiang Lin* and Yinhua Ma* \\ *College of Agriculture and Biotechnology, Hunan University of Humanities, Science and Technology, Loudi, \\ Hunan, 417000, China \\ †Corresponding author: Minyi Huang; huang.m.y@ 163.com
}

\section{Nat. Env. \& Poll. Tech.} Website: www.neptjournal.com

Received: 28-10-2019

Revised: 18-11-2019

Accepted: 16-01-2020

Key Words:

Atrazine

Pelophylax nigromaculatus

Oxygen consumption

Tadpoles

\begin{abstract}
Amphibians grow and reproduce in water, and are sensitive to water pollution. Atrazine is one of the widely distributed herbicides that can damage the amphibians. To study the influence of atrazine on the growth, development and oxygen consumption of Pelophylax nigromaculata larvae, 26 stages of tadpoles were raised in water containing different concentrations of atrazine $(0,8,16,32$ and 64 $\mu \mathrm{g} / \mathrm{L})$. After treatments at different times $(10,15,20,25 \mathrm{~d})$, the snout vent length $(\mathrm{SVL})$, total length, body width and the bodyweight of tadpoles were measured, and oxygen consumption of tadpoles was checked with an aquatic biorespirometer. The results showed that with the increase of treatment time, the SVL, whole length, body width and the bodyweight of $P$. nigromaculatus tadpoles of each concentration group increased. At the same treatment time, the SVL, whole length, body width and the bodyweight of $P$. nigromaculatus tadpoles gradually decreased with the increase of concentration. Compared with the control group, the oxygen consumption in the treatment groups increased in the short-term treatment $(10 \mathrm{~d})$, had no difference in the medium-term treatment $(15 \mathrm{~d})$ and decreased in the long-term treatment (20 and $25 \mathrm{~d})$.
\end{abstract}

\section{INTRODUCTION}

Atrazine is a kind of ubiquitously used pesticide herbicide in farmland ecosystems for its low cost and good weeding effect (Solomon et al. 2008, Figueira et al. 2017). Atrazine is highly polar and soluble in water. It has a long residual period in the environment and has highly toxic bio-accumulation. Atrazine is dissolved in the waters around farmlands after extensive use, which has harmful effects on the ecological environment and animal survival.

Atrazine can have harmful effects on fish, amphibians and aquatic reptiles, which can be accumulated in organisms and easily absorbed by skin, respiratory tract and digestive tract (Solomon et al. 2008). Atrazine can produce neurotoxicity mainly including oxidative stress injury, neurotransmitter disorder and neurocyte injury (Jin et al. 2014). At the same time, it can affect the synthesis, release, transmission and sensitivity of neurotransmitters, inhibit the transmission speed of excitation, lead to changes in the morphology of the central nervous system, and damage neurons and glial cells (Figueira et al. 2017). Atrazine can also induce oxidative stress, lipid peroxidation and enzyme activity, leading to neurological disorders, affecting the balance between activation and inhibition of synaptic transmission (Schmidel et al. 2014). Atrazine can significantly affect estrogen receptors by interacting with them (Albanito et al. 2015).

Amphibians are extremely sensitive to the changes in waters and their surrounding environments. In recent years, the number of amphibian population has been decreasing rapidly. Atrazine in water is one of the main reasons for the decrease in amphibians. Studies have been done on the effects of atrazine on fish, reptiles, birds and mammals, however, studies on the effects of atrazine on amphibians mainly focus on embryonic development, tissue damage, oxidative stress, and so on (Mitchkash et al. 2014, Brodkin et al. 2007, Orton et al. 2006, Tavera-Mendoza et al. 2002). For example, atrazine can affect an individual's survival, development and motor retardation of Limnodynastes peronii (Mitchkash et al. 2014). Atrazine can reduce the number of white cells in Rana pipiens and affected the activity of phagocytes (Brodkin et al. 2007). Atrazine can change the ratio of male to female, resulting in a reduction of sperm cells in the testis of $R$. pipiens (Orton et al. 2006). Tadpoles of Xenopus laevis, exposed to atrazine $(21 \mu \mathrm{g} / \mathrm{L})$ for 48 hours, can cause a $57 \%$ reduction in testicular volume and a $7 \%$ reduction in the number of germ cells (Tavera-Mendoza et al. 2002).

Different species have different sensitivities to atrazine, especially in embryonic and metamorphic individuals, which are more sensitive to atrazine (Allran \& Karasov 2010). 
Respiration is an activity of gas exchange between animals and the outside medium, which plays an important role in the survival of animals. Most of the studies on oxygen consumption are focused on the invertebrates, fish or mammals (Lee et al. 2003, Lamarre et al. 2016), but less on amphibian tadpoles, especially on the effects of atrazine on the respiratory capacity of tadpoles.

Pelophylax nigromaculatus is a widely distributed species in farmland in China, which is greatly affected by environmental pollution. In this study, P. nigromaculatus tadpoles were exposed to water containing different concentrations of atrazine, and the effects of different treatment time and concentration of atrazine on the growth, development and oxygen consumption of $P$. nigromaculatus tadpoles were studied.

\section{MATERIALS AND METHODS}

Sexually matured individuals of P. nigromaculatus were collected in the field and mated in the laboratory. Fertilized eggs were hatched after frogs spawning, until 26 stages. Healthy and similar size tadpoles were selected for the experiment. The atrazine with a purity of $38 \%$ used was procured from Bonong Chemical Technology Co., Ltd. of China. The mother liquor of $1 \mathrm{~g} / \mathrm{L}$ atrazine was prepared with pure water.

When the tadpoles reached stage 26 , four treatment groups and one control group were set up. The treatments of atrazine were of $8,16,32$ and $64 \mu \mathrm{g} / \mathrm{L}$ respectively, and three corresponding parallel groups were set up in each treatment. Each group contained 20 similar and healthy tadpoles, which were fed in $4 \mathrm{~L}$ water which was aerated for more than 3 days. During the experiment, soybean milk residue was fed at 8 a.m. every day. After 2 hours of feeding, the water was changed. During the experiment, the water temperature was $21-23^{\circ} \mathrm{C}$, the dissolved oxygen was $6.8-7.5 \mathrm{mg} . \mathrm{L}^{-1}$, the relative humidity in the air was $65 \%-73 \%$, and the dark:light period in the laboratory was $12 \mathrm{~h}: 12 \mathrm{~h}$. The experiment was supported by the local government, and the breeding and use of experimental animals followed the committee principles.

After different times of treatments (10, 15, 20 and $25 \mathrm{~d})$, the snout vent length (SVL), total length, body width and the bodyweight of tadpoles were measured respectively by the digital Vernier calliper, and oxygen consumption of tadpoles was assessed with an aquatic biorespirometer (Q-Box AQUA Aquatic Respirometry, Qubit Systems Inc. Kingston, Ontario, Canada). The system uses a cylindrical breathing chamber ( $3.7 \mathrm{~cm}$ diameter, $15 \mathrm{~cm}$ long) which is installed in an improved insulated cooler used as an experimental chamber. During the whole experiment, the oxygen consumption measurement was recorded every 5 minutes.

The Statistic software was used for statistical analysis of data, and one-way ANOVA analysis was conducted among groups, $P<0.05$ was considered as a significant difference.

\section{RESULTS}

Compared with the low concentration group $(8 \mu \mathrm{g} / \mathrm{L})$ and the control group, the high concentration groups $(16,32$ and $64 \mu \mathrm{g} / \mathrm{L}$ ) had a smaller size and slower movement under the same treatment time (Fig. 1). In the high concentration groups $(16,32$ and $64 \mu \mathrm{g} / \mathrm{L})$ treated for 25 days, some individuals

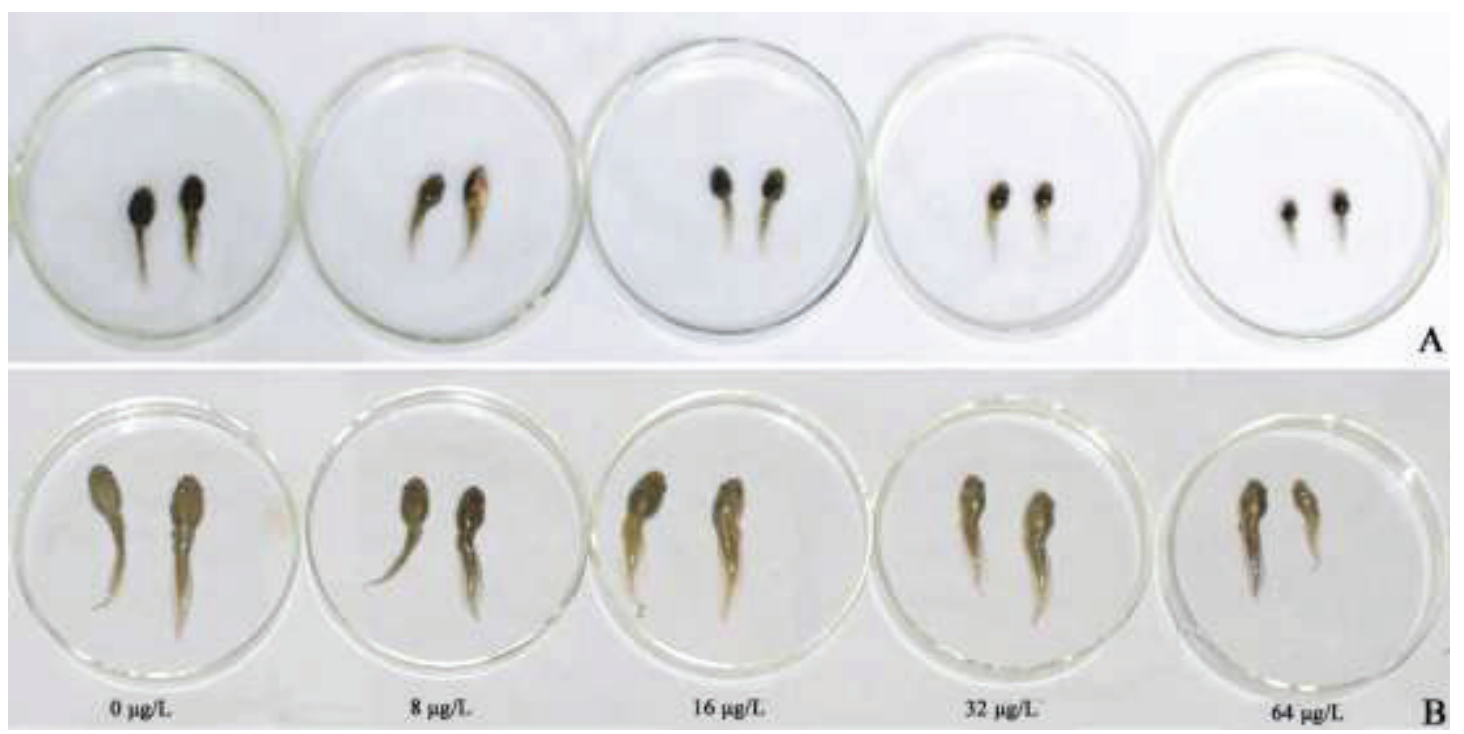

Fig. 1: The morphological size in P. nigromaculata under the different atrazine concentrations $(0,8,16,32$ and $64 \mu \mathrm{g} / \mathrm{L})$ and different test times (A 10 days, B 25 days). 
were observed to have body bending, abnormal eyes and other deformities (Fig. 1).

With the increase of treatment time, the SVL, whole length and body width of each concentration group increased (Figs. 2, 3, 4). At the same treatment time, the SVL, whole length and body width gradually decreased with the increase of concentration (Figs. 2, 3, 4).

After 10 and 15 days of treatment, there was no significant difference in the SVL, whole length and body width between the high concentration groups (32 and $64 \mu \mathrm{g} / \mathrm{L}$ ),

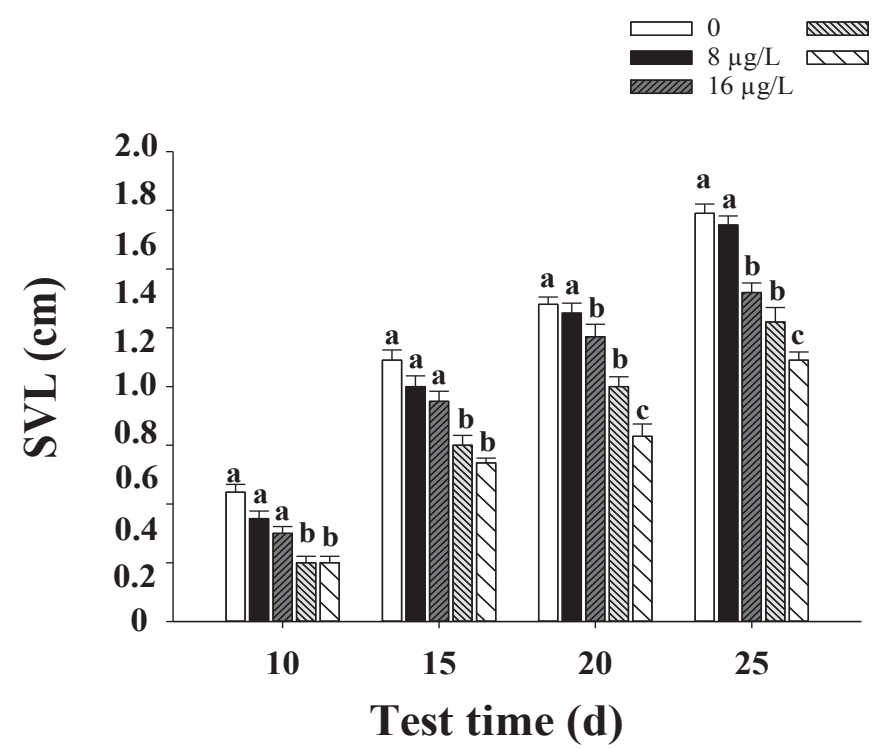

Fig. 2: The snout vent length (SVL) in P. nigromaculata under the different atrazine concentrations $(0,8,16,32$ and $64 \mu \mathrm{g} / \mathrm{L})$ and different test times $(10,15,20$ and $25 \mathrm{~d})$. Values represent the mean \pm SE. Treatments with different letters differ significantly $($ Tukey’s test, $a=0.05, a>b>c)$.

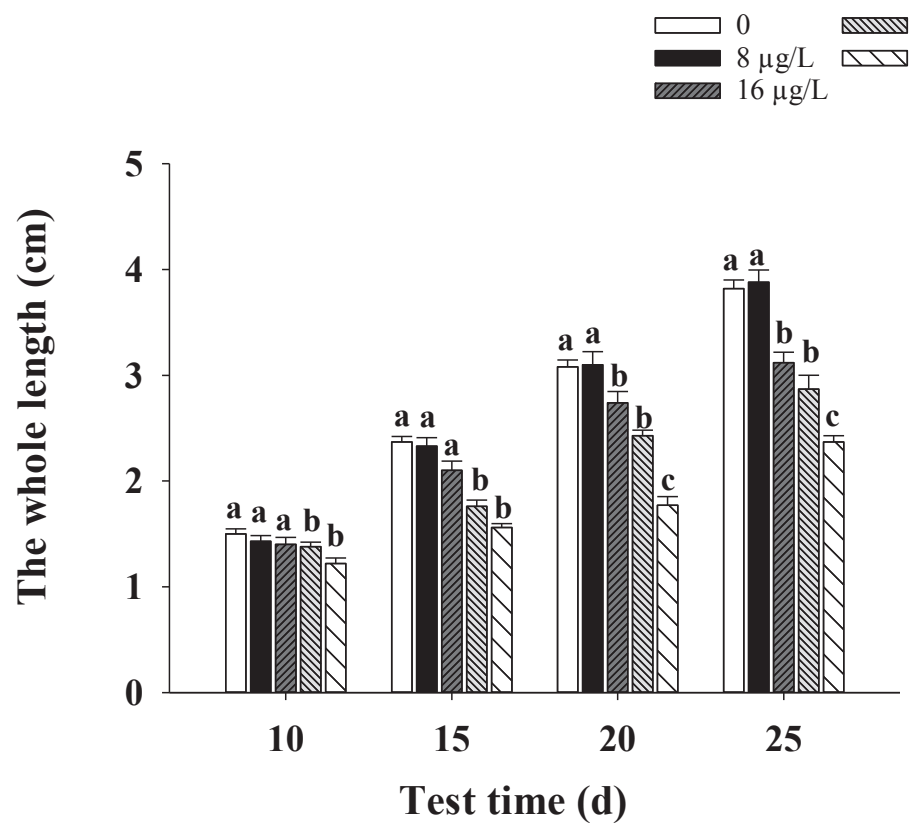

Fig. 3: The whole length in $P$. nigromaculata under the different atrazine concentrations $(0,8,16,32$ and $64 \mu \mathrm{g} / \mathrm{L})$ and different test times $(10,15,20$ and $25 \mathrm{~d}$ ). Values represent the mean \pm SE. Treatments with different letters differ significantly (Tukey's test, $\mathrm{a}=0.05, \mathrm{a}>\mathrm{b}>\mathrm{c}$ ). 


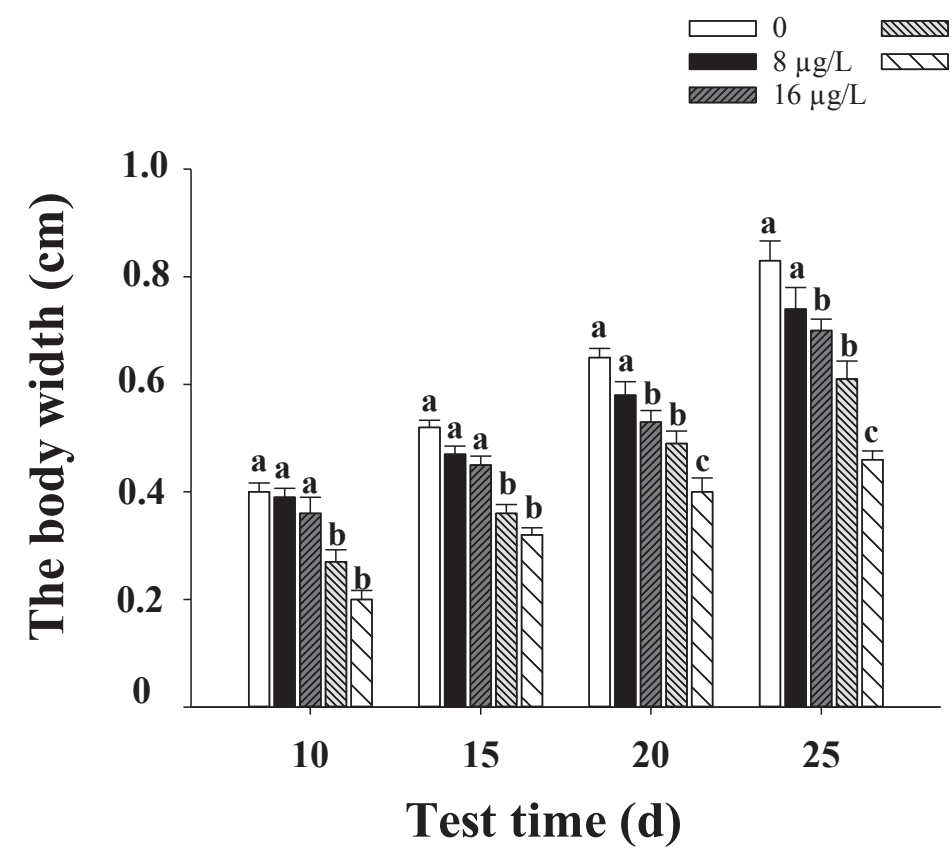

Fig. 4: The body width in P. nigromaculata under the different atrazine concentrations $(0,8,16,32$ and $64 \mu \mathrm{g} / \mathrm{L})$ and different test times $(10,15,20$ and $25 \mathrm{~d}$ ). Values represent the mean \pm SE. Treatments with different letters differ significantly (Tukey's test, $\mathrm{a}=0.05, \mathrm{a}>\mathrm{b}>\mathrm{c}$ ).

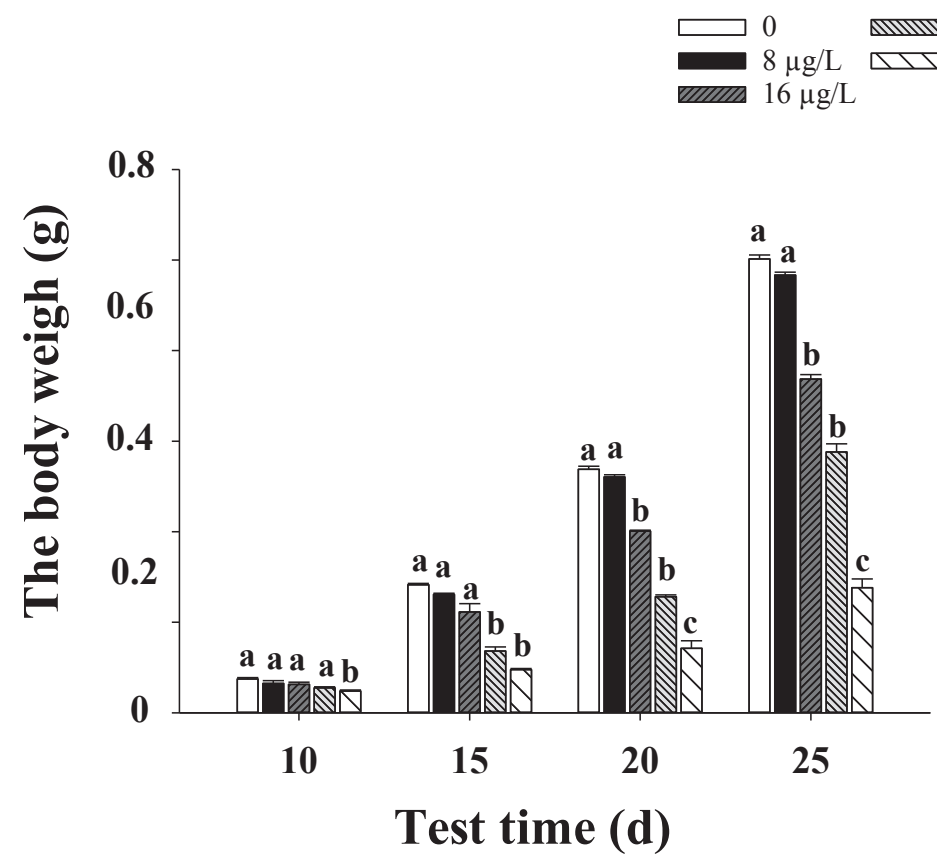

Fig. 5: The body weight in $P$. nigromaculata under the different atrazine concentrations $(0,8,16,32$ and $64 \mu \mathrm{g} / \mathrm{L})$ and different test times $(10,15,20$ and $25 \mathrm{~d}$ ). Values represent the mean \pm SE. Treatments with different letters differ significantly (Tukey's test, $a=0.05, a>b>c$ ). 
but they were significantly lower than other treatments $(P$ $<0.05$ ) (Figs. 2, 3, 4). After 20 and 25 days of treatment, the SVL, whole length and body width in $64 \mu \mathrm{g} / \mathrm{L}$ treatment group were the lowest, significantly lower than those of other treatment groups $(P<0.05)$. There was no significant difference in the SVL, whole length and body width in the 16 and $32 \mu \mathrm{g} / \mathrm{L}$ treatment groups $(P>0.05)$, but they were significantly lower than those of $8 \mu \mathrm{g} / \mathrm{L}$ treatment group and control group $(P<0.05)$ (Figs. 2, 3, 4).

With the increase of treatment time, the body weight of each concentration group increased (Fig. 5). At the same treatment time, the body weight gradually decreased with the increase of concentration (Fig. 5).

After 10 days of treatment, the high concentration group $(64 \mu \mathrm{g} / \mathrm{L})$ was significantly lower than other treatments $(P<$ $0.05)$, and there was no significant difference among other treatments $(0,8,16$ and $32 \mu \mathrm{g} / \mathrm{L})(P>0.05)$ (Fig. 5). After 15 days of treatment, there was no significant difference between the 64 and $32 \mu \mathrm{g} / \mathrm{L}$ treatment groups $(P>0.05)$, but they were significantly lower than other treatment groups ( $P$ $<0.05$ ) (Fig. 5). After 20 days and 25 days, the changes of body weight were similar. The $64 \mu \mathrm{g} / \mathrm{L}$ treatment group was the lowest, significantly lower than other treatment groups
$(P<0.05)$. There was no significant difference between the 16 and $32 \mu \mathrm{g} / \mathrm{L}$ treatment groups $(P>0.05)$, but they were significantly lower than the $8 \mu \mathrm{g} / \mathrm{L}$ treatment group and the control group $(P<0.05)$ (Fig. 5).

Oxygen consumptions of $P$. nigromaculatus tadpoles in different concentrations at 10, 15, 20 and 25 days treatment were measured by a respirometry system (Fig. 6). There was no significant difference between body weight and oxygen consumption in tadpole $(P>0.05)$. With the extension of treatment time, the oxygen consumption of each concentration group increased. But under the same treatment time, with the increase of treatment concentration, the oxygen consumption showed a variety of changes (Fig. 6).

After treatment for 10 days, oxygen consumption increased with the increase of treatment concentration. Compared with the control group, the oxygen consumption of the treatment group was significantly higher than that of the control group $(P<0.05)$. High concentration treatment groups (32 and $64 \mu \mathrm{g} / \mathrm{L}$ ) were significantly higher than other treatments $(P<0.05)$, and there was no significant difference among other treatments $(0,8$ and $16 \mu \mathrm{g} / \mathrm{L})(P>0.05)$ (Fig. $6)$. After 15 days of treatment, with the increase of treatment concentration, oxygen consumption showed a waveform
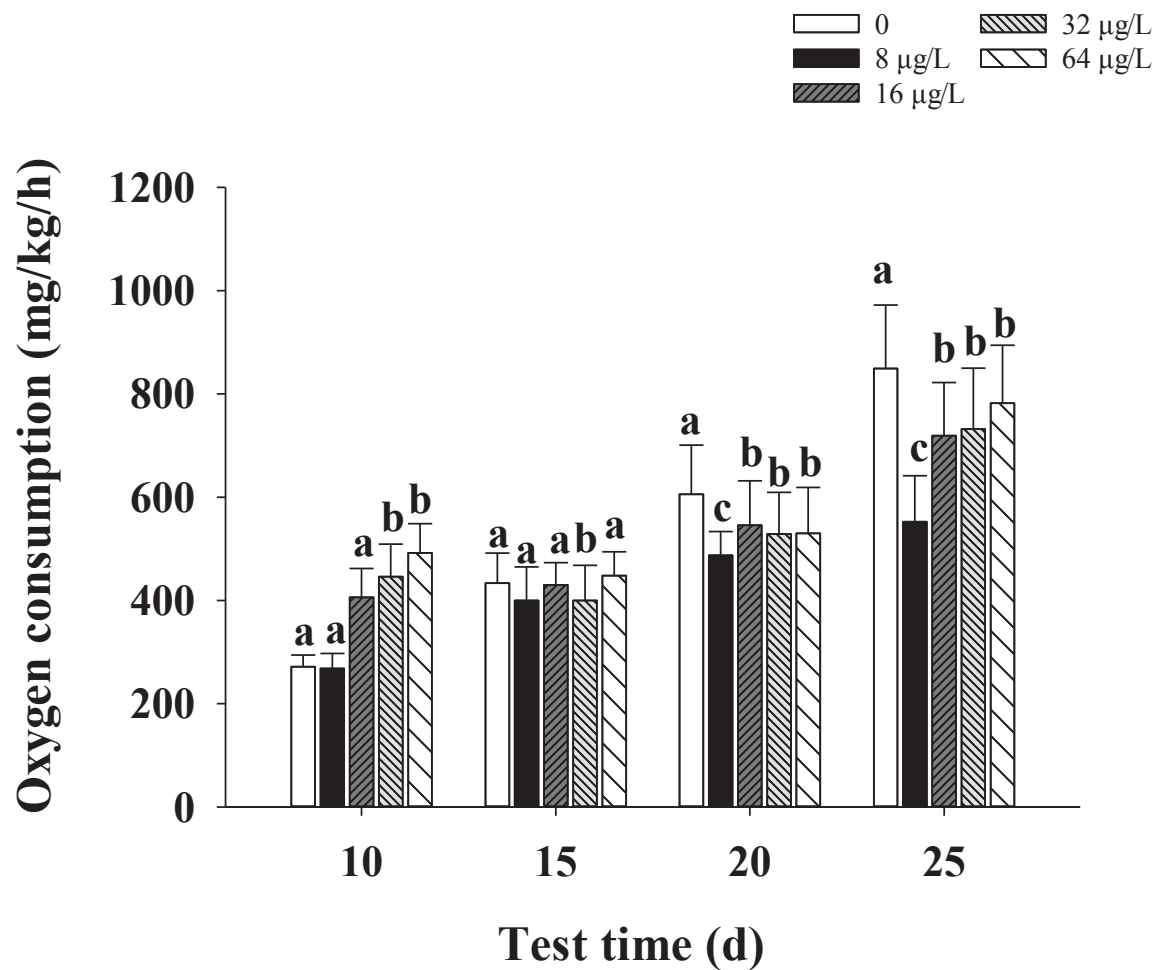

Fig. 6: The oxygen consumption of tadpoles in P. nigromaculata under the different atrazine concentrations $(0,8,16,32 \mathrm{and} 64 \mu \mathrm{g} / \mathrm{L})$ and different test times $(10,15,20$ and $25 \mathrm{~d})$. Values represent the mean \pm SE. Treatments with different letters differ significantly $($ Tukey's test, $a=0.05$, $a>b>c)$. 
change. On the whole, there was no significant difference between the treatment group and the control group $(P>0.05)$. After 20 and 25 days of treatment, oxygen consumption showed waveform change. Compared with the control group, the oxygen consumption of the treatment group showed a downward trend. Among them, $8 \mu \mathrm{g} / \mathrm{L}$ treatment group was the lowest $(P<0.05)$ (Fig. 6).

\section{DISCUSSION}

Because tadpoles live in water, they are more sensitive to pollutants where they live. With the prolongation of exposure time, their snout vent length (SVL), whole length, body width and body weight increased, however, with the increasing of concentration, relative to the control, the growth of tadpoles decreased obviously. This indicated that certain concentrations of atrazine influence the growth and development of tadpole in a certain period, which is similar to other studies (Freeman et al. 2005, Mitchkash et al. 2014, Mendonça et al. 2016). Mendonça et al. (2016) documented that atrazine exposure can lead to a slower rate of metamorphosis in Podocnemis expansa, resulting in decreased swimming and leaping ability of individuals. Mitchkash et al. (2014) also found that atrazine could affect individual survival, development and motor retardation in Limnodynastes peronii. The growth retardation of tadpoles by atrazine may be due to the influence of atrazine on the thyroid in Bufo americanus tadpoles (Freeman et al. 2005).

The respiratory system can quickly respond to the changes in the external environment, so it is an important indicator of the body's functional state. Amphibian larvae live in water and breathe by gills. Moreover, the skin of tadpole has good permeability. Therefore, tadpoles' respiratory system is susceptible to the influence of their living water. It was reported that atrazine can induce respiratory difficulty in adult $R$. pipiens by increasing buccal and thoracic ventilation (Allran \& Karasov 2010). The acute exposure of atrazine $(8.1 \mathrm{mg} / \mathrm{L})$ can alter routine oxygen consumption in Tilapia sparrmanii, especially reflecting a drastic decrease within 3 hours (Grobler et al. 1989).

There is a certain correlation between oxygen consumption and treatment time. Our findings confirm that atrazine affected oxygen consumption of tadpoles in P. nigromaculata. Compared with the control group, the oxygen consumption in the treatment groups increased in the short-term treatment (10 d), had no difference in the medium-term treatment (15 d) and decreased in the long-term treatment ( $20 \mathrm{~d}$ and $25 \mathrm{~d})$. Other studies have similar findings. For example, atrazine $(150 \mu \mathrm{g} / \mathrm{L})$ can induce respiratory oxygen consumption increasing in 2-day postfertilization fathead minnow ( $P i$ mephales promelas) eggs after using the self-referencing micro-optrode technique after $2 \mathrm{~h}$ exposures to atrazine (Sanchez et al. 2008). The long-term atrazine treatment can lead to changes in morphological damage of the respiratory tract, which induce a decrease in oxygen consumption. Previous studies have shown that herbicides can cause significant changes in skin morphology, cell and epithelial cell proliferation or hypertrophy and chromatid breakdown, and affect the physiology of respiratory tract morphology in bullfrog tadpoles (Rissoli et al. 2016). High concentration atrazine can cause blood composition and oxygen consumption change in Tilapia mossambica, which induce respiratory distress in fish (Prasad et al. 1991).

\section{ACKNOWLEDGEMENTS}

This work was supported by the National Natural Science Foundation of China (31970494) and the Natural Science Foundation of Hunan (2019JJ40138).

\section{REFERENCES}

Albanito, L., Lappano, R., Madeo, A., Chimento, A., Prossnitz, E.R., Cappello, A.R., Dolce, V., Abonante, S., Pezzi, V. and Maggiolini, M. 2015. Effects of atrazine on estrogen receptor $\alpha$ - and $G$ protein-coupled receptor 30-mediated signalling and proliferation in cancer cells and cancer-associated fibroblasts. Environ. Health. Perspect., 123: 493-499.

Allran, J.W. and Karasov, W.H. 2010. Effects of atrazine on embryos, larvae, and adults of anuran amphibians. Environ. Toxicol. Chem., 20(4): 769-775.

Brodkin, M.A., Madhoun, H., Rameswaran, M. and Vatnick, I. 2007. Atrazine is an immune disruptor in adult northern leopard frogs (Rana pipiens). Environ. Toxicol. Chem., 26: 80-84.

Figueira, F.H., de Quadros Oliveira, N., de Aguiar, L.M., Escarrone, A.L., Primel, E.G., Barros, D.M. and da Rosa, C.E. 2017. Exposure to atrazine alters behaviour and disrupts the dopaminergic system in Drosophila melanogaster. Comp. Biochem. Physiol. C Toxicol. Pharmacol., 202: 94-102.

Freeman, J.L., Beccue, N. and Rayburn, A.L. 2005. Differential metamorphosis alters the endocrine response in anuran larvae exposed to $\mathrm{T}_{3}$ and atrazine. Aquat. Toxicol., 75(3): 263-276.

Grobler, E., Vuren, J. H.J.V. and Preez, H.H.D. 1989. Routine oxygen consumption of Tilapia sparrmanii (cichlidae) following acute exposure to atrazine. Comp. Biochem. Physiol. C Toxicol. Pharmacol., 93(1): 37-42.

Jin, Y., Wang, L., Chen, G., Lin, X., Miao, W. and Fu, Z. 2014. Exposure of mice to atrazine and its metabolite diaminochlorotriazine elicits oxidative stress and endocrine disruption. Environ. Toxicol. Pharmacol., 37(2): 782-90.

Lamarre, S.G., Maccormack, T.J., Sykes, A.V., Hall, J.R. Speers-Roesch, B., Callaghan, N.I. and Driedzic, W.R. 2016. Metabolic rate and rates of protein turnover in food deprived cuttlefish, Sepia officinalis (Linnaeus 1758). Am. J Physiol. Regul. Integr. Comp. Physiol., 310(11): 1160-1168.

Lee, C. G., Farrell, A. P., Lotto, A., MacNutt, M.J., Hinch, S.G. and Healey, M.C. 2003. The effect of temperature on swimming performance and oxygen consumption in adult sockeye (Oncorhynchus nerka) and coho (O. kisutch) salmon stocks. J. Exp. Biol., 206(18): 3239-3251.

Mendonça, J. S., Vieira, L.G., Valdes, S.A., Vilca, F.Z., Tornisielo, V.L. and Santos, A.L. 2016. Effects of the exposure to atrazine on bone development of Podocnemis expansa (Testudines, Podocnemididae). Ecotoxicology, 25: 594-600. 
Mitchkash, M.G., McPeek, T. and Boone, M.D. 2014. The effects of 24-h exposure to carbaryl or atrazine on the locomotor performance and overwinter growth and survival of juvenile spotted salamanders (Ambystoma maculatum). Environ. Toxicol. Chem., 33: 548-552.

Orton, F., Carr, J.A. and Handy, R.D. 2006. Effects of nitrate and atrazine on larval development and sexual differentiation in the northern leopard frog Rana pipiens. Environ. Toxicol. Chem., 25: 65-71.

Prasad, T.A., Srinivas, T., Rafi, G.M. and Reddy, D.C. 1991. Effect in vivo of atrazine on haematology and $\mathrm{O}_{2}$ consumption in fish, Tilapia mossambica. Biochem. Int., 23(1): 157.

Rissoli, R.Z., Abdalla, F.C., Costa, M.J., Rantin, F., McKenzie, D.J. and Kalinin, A.L. 2016. Effects of glyphosate and the glyphosate based herbicides Roundup Original and Roundup Transorb on respiratory morpho physiology of bullfrog tadpoles. Chemosphere, 156: 37-44.

Sanchez, B.C., Ochoaacuña, H., Porterfield, D.M. and Sepúlveda, M.S. 2008. Oxygen flux as an indicator of physiological stress in fathead minnow (Pimephales promelas) embryos: A real-time biomonitoring system of water quality. Environ. Sci. Technol., 42(18): 7010-7017.

Schmidel, A.J., Assmann, K.L., Werlang, C.C., Bertoncello, K.T., Francescon, F., Rambo, C.L., Beltrame, G.M., Calegari, D., Batista, C.B., Blaser, R.E., Roman Júnior, W.A., Conterato, G.M., Piato, A.L., Zanatta, L., Magro, J.D. and Rosemberg, D.B. 2014. Subchronic atrazine exposure changes defensive behaviour profile and disrupts brain acetylcholinesterase activity of zebrafish. Neurotoxicol. Teratol., 44: 62- 69.

Solomon, K.R., Carr, J.A., Du Preez, L.H., Giesy, J.P., Kendall, R.J., Smith, E.E. and Van Der Kraak, G.J. 2008. Effects of atrazine on fish, amphibians, and aquatic reptiles: A critical review. Crit. Rev. Toxicol., 38(9):721-772.

Tavera-Mendoza, L., Ruby, S., Brousseau, P., Fournier, M., Cyr, D. and Marcogliese, D. 2002. Response of the amphibian tadpole (Xenopus laevis) to atrazine during sexual differentiation of the testis. Environ. Toxicol. Chem., 21: 527-531. 